09

\title{
Внутрирезонаторная волноводная спектроскопия тонких пленок
}

\author{
(C) А.В. Шульга, А.В. Хомченко , И.В. Шилова
}

Белорусско-Российский университет, Могилев, Беларусь

ฯE-mail: avkh@mogilev.by

Поступило в Редакцию 5 июня 2018 г.

Предложен метод внутрирезонаторной волноводной спектроскопии для измерения малых оптических потерь в тонких пленках, который также позволяет осуществлять дискриминацию поперечных и продольных мод в лазерах с малым коэффициентом усиления без внесения в резонатор значительных потерь.

DOI: $10.21883 /$ PJTF.2018.21.46849.17418

Тонкопленочные диэлектрические структуры находят широкое применение при создании элементов интегрально-оптических устройств, отражающих и делительных элементов силовой оптики. Одной из основных характеристик таких структур является их оптическая прозрачность, обусловленная низким уровнем примесей в материале тонкопленочной структуры, приводящих к поглощению излучения и, как следствие, изменению ее рабочих характеристик (оптический пробой, возникновение механических напряжений и т.д.). Методы волноводной спектроскопии[1], основанные на регистрации пространственного распределения интенсивности светового пучка, отраженного от призменного устройства возбуждения волноводной моды тонкопленочной структуры, представляют определенный интерес для измерения параметров тонких пленок с малыми оптическими потерями [2-4]. При этом угловое распределение интенсивности отраженного светового пучка в 
случае возбуждения волноводной моды определяется оптическими свойствами волновода, в частности постоянной распространения $h$ волноводной моды. Контраст регистрируемого распределения и точность определения мнимой части постоянной распространения $h^{\prime \prime}$ существенно зависят от толщины буферного слоя, что затрудняет исследование тонкопленочных структур и нанослоев с малыми оптическими потерями, для которых $h^{\prime \prime}<10^{-5}$. Для решения данной проблемы было предложено использование принципов внутрирезонаторной лазерной спектроскопии [5], точнее, внутрирезонаторного возбуждения волноводных мод, что дает возможность измерять сверхмалые потери в тонких пленках.

В настоящей работе рассмотрены особенности применения внутрирезонаторной волноводной спектроскопии для измерения параметров тонкопленочных структур с малыми оптическими потерями, а также возможность использования данного подхода для дискриминации поперечных и продольных лазерных мод.

Известно, что при внутрирезонаторной лазерной спектроскопии небольшие изменения коэффициентов поглощения внутрирезонаторных элементов приводят к значительным изменениям мощности выходного лазерного излучения [5]. Если коэффициент усиления резонатора не превышает оптических потерь, то генерация излучения не наблюдается [6], что уверенно регистрируется при использовании лазеров с низким коэффициентом усиления. В связи с этим внутрирезонаторную лазерную спектроскопию можно использовать в качестве высокочувствительного метода измерения сверхмалых оптических потерь.

Принципиальная схема установки внутрирезонаторной волноводной спектроскопии представлена на рис. 1, $a$. Непосредственное размещение классической призмы связи в резонаторе неизбежно приведет к срыву генерации излучения лазера, так как вращение призмы связи вызовет разъюстировку резонатора. Кроме того, френелевские потери на гранях призмы и оптические потери материала призмы связи также могут превышать коэффициент усиления лазера. Для устранения указанных недостатков призма связи из оптически прозрачного материала (сверхтяжелый крон СТК3) была изготовлена в форме наклонного параллелепипеда. При помещении призмы в резонатор гелий-неонового лазера излучение претерпевает полное внутреннее отражение на обеих гранях, сохраняя при этом углы падения и пропускания неизменными. Для уменьшения френелевских потерь призма связи изготавливалась таким образом, чтобы свет после отражения от основания призмы попадал

Письма в ЖТФ, 2018, том 44, вып. 21 

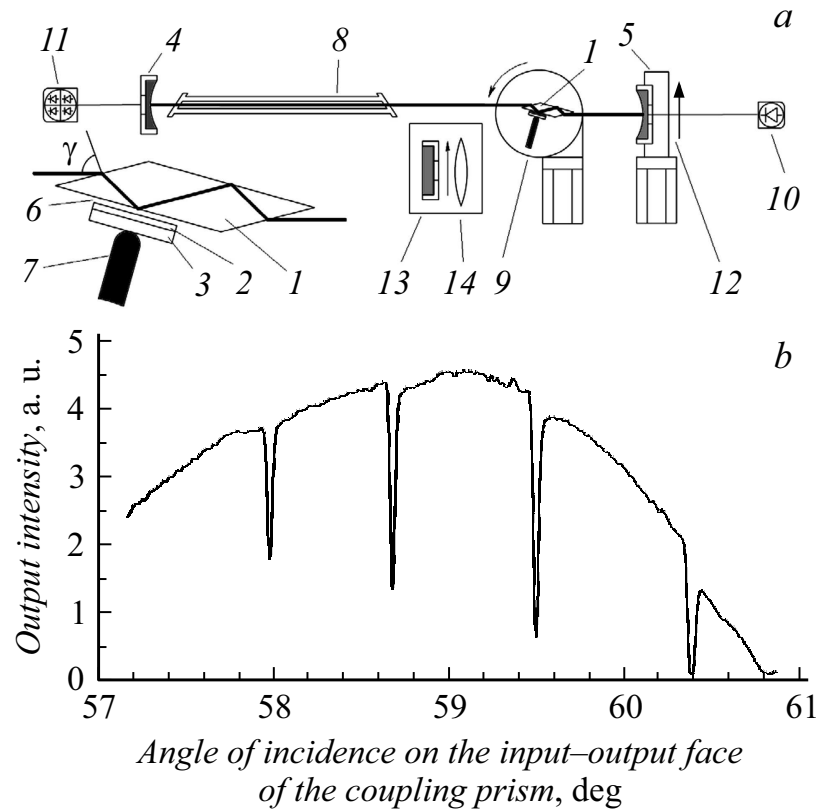

Рис. 1. $a-$ схема установки внутрирезонаторной волноводной спектроскопии: 1 - призма связи, 2 - волновод, 3 - подложка, $4-$ „квазиглухое“ зеркало, 5 - выходное зеркало, 6 - воздушный зазор, 7 - прижимной винт, $8-$ газоразрядная трубка гелий-неонового лазера, 9 - поворотная платформа, 10 - фотоприемник, 11 - координатный фотодиод, 12 - платформа продольного перемещения, 13 - плоское выходное зеркало, 14 - линза; $b$ - зависимость интенсивности внутрирезонаторного излучения на выходе от углового положения призмы связи.

на выходную грань призмы под углом, близким к углу Брюстера. Брюстеровская призма связи 1 с волноводом 2 на стеклянной подложке 3 помещается в резонатор лазера, состоящего из двух сферических зеркал: „квазиглухого“ 4 и выходного 5 . Толщина воздушного зазора 6 контролируется прижимным винтом 7. Брюстеровская призма связи находится между выходным зеркалом и газоразрядной трубкой 8 гелийнеонового лазера. Угловое положение призмы с заданной точностью изменяется поворотной платформой 9, приводимой в движение шаговым

Письма в ЖТФ, 2018, том 44, вып. 21 
двигателем. Интенсивность выходного излучения лазера регистрируется фотоприемником 10. Излучение, выходящее из „квазиглухого“ зеркала, регистрируется координатным (сегментным) фотодиодом 11. Установка настраивается таким образом, чтобы получить максимум излучения, регистрируемого фотоприемником 10. Для обеспечения неизменности углового положения лазерного луча держатель выходного зеркала помещался на платформе продольного перемещения 12. В начальный момент времени координатный фотодиод устанавливался таким образом, чтобы излучение лазера попадало в его центр. Поворот призмы связи приводит к угловому сдвигу лазерного пучка, что регистрируется координатным фотодиодом в виде разности интенсивностей сигналов от правых и левых его сегментов. Платформа 12 перемещает выходное зеркало в направлении, перпендикулярном оптической оси лазера до восстановления первоначальной интенсивности сигналов, что может свидетельствовать об установке первоначального углового направления распространения излучения. Только после этого производится регистрация выходного излучения лазера фотоприемником 10. Зазор между волноводом и призмой связи регулировался прижимным винтом для обеспечения наибольшего контраста интенсивности. Таким образом была обеспечена возможность регистрации угловой зависимости интенсивности светового пучка, отраженного от призменного устройства возбуждения волноводной моды (спектров отражения), в большом угловом диапазоне без срыва генерации излучения.

Для сравнения результатов измерений с данными, полученными традиционным ,внерезонаторным“ методом, в экспериментальную установку между газоразрядной трубкой гелий-неонового лазера и призмой связи было введено дополнительное плоское выходное зеркало $13 \mathrm{c}$ фурье-линзой 14 . В качестве тестового образца использовался пятимодовый ионообменный волновод с низкими потерями. Оптические параметры данного волновода были измерены независимым методом [1]. Для мод, зарегистрированных внутрирезонаторным методом, мнимая часть постоянной распространения $\operatorname{Im}\left(h / k_{0}\right)$ составляла величину $\sim 10^{-5}$ (см. таблицу). Зарегистрированные спектры внутрирезонаторного отражения представлены на рис. $1, b$.

Представленные данные показывают, что метод внутрирезонаторной волноводной спектроскопии позволяет регистрировать спектры отражения в случае слабой связи. Следует отметить, что спектры „внерезонаторного“ возбуждения тестового волновода не имеют резонансных минимумов при обеспечении слабой связи и могут наблюдаться

Письма в ЖТФ, 2018, том 44, вып. 21 
Оптические параметры волноводной структуры

\begin{tabular}{c|c|c}
\hline Номер моды & $\operatorname{Re}\left(h / k_{0}\right)$ & $\operatorname{Im}\left(h / k_{0}\right), 10^{-5}$ \\
\hline 1 & 1.53359 & 3.7 \\
2 & 1.52863 & 3.1 \\
3 & 1.52384 & 1.5 \\
4 & 1.51928 & 2.6
\end{tabular}

только при сильном его прижиме к призме связи, что подтверждает преимущества внутрирезонаторного метода при исследовании слабопоглощающих тонкопленочных структур. При этом вносимые в лазерный резонатор оптические потери $\sim 5 \cdot 10^{-6}$ уверенно регистрируются в представленной схеме (рис. $1, b)$.

Частотно-угловая селективность оптического поглощения призменного устройства связи [4] позволяет использовать его в качестве источника вносимых контролируемых внутрирезонаторных потерь. На рис. 2, a приведена принципиальная схема установки, используемой для внутрирезонаторной дискриминации поперечных мод лазера, где в качестве источника селективных потерь применялось „брюстеровское“ призменное устройство связи с планарным диэлектрическим волноводом с малыми оптическими потерями. Призма устанавливалась внутри резонатора таким образом, чтобы внутрирезонаторное излучение также претерпевало двукратное внутреннее отражение с возбуждением планарного волновода. С помощью углового перемещения призменного устройства связи осуществлялась его селективность к угловому распределению внутрирезонаторного излучения, что позволяло избирательно вносить внутрирезонаторные потери для мод заданных порядков. На рис. 2, $b$ представлено зарегистрированное угловое распределение интенсивности первой моды резонатора гелий-неонового лазера, образованного сферическими зеркалами (сплошная кривая), а также рассчитанное распределение интенсивности (пунктирная кривая) излучения для лазерного резонатора с соответствующими физическими параметрами. Результаты расчетов удовлетворительно коррелируют с данными измерений, которые показали принципиальную возможность предложенного метода внутрирезонаторной дискриминации поперечных мод лазера.

Письма в ЖТФ, 2018, том 44, вып. 21 

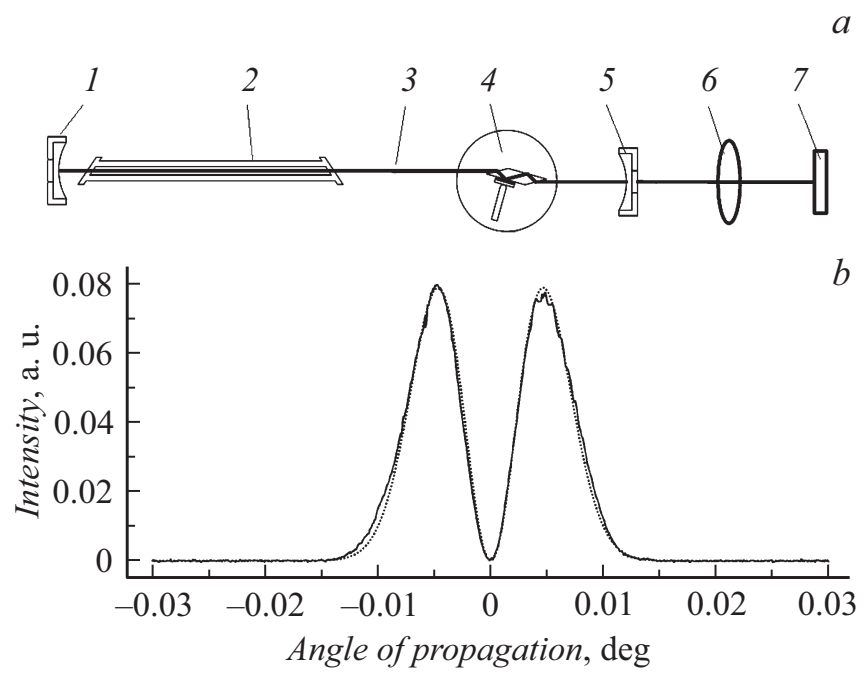

Рис. 2. $a-$ схема установки для осуществления внутрирезонаторной дискриминации поперечных мод лазера: 1 - „глухое“ зеркало, 2 - активный элемент, 3 - излучение, 4 - поворотная платформа с призменным устройством связи, 5 - выходное зеркало, 6 - линза, осуществляющая фурье-преобразование, 7 - фотолинейка; $b$ - измеренное (сплошная линия) и рассчитанное (пунктир) распределения интенсивности первой моды излучения лазера.

Таким образом, предложенная конструкция брюстеровского призменного устройства связи делает возможным использование планарных оптических волноводов в качестве источника внутрирезонаторных лазерных потерь с частотно-угловой селекцией. Применение волноводов с малыми оптическими потерями позволяет управлять интенсивностью внутрирезонаторного излучения без срыва генерации. Анализ зарегистрированных угловых зависимостей интенсивности света, отраженного вблизи углов возбуждения волноводных мод, показывает, что внутрирезонаторная спектроскопия волноводных мод обеспечивает высокий контраст регистрации распределения интенсивности излучения по сравнению с традиционными методами. Высокая чувствительность предложенного метода позволяет измерять малые оптические потери в случае слабой связи призмы и волновода и минимизировать влияние призмы связи на результаты измерения. Следует отметить,

Письма в ЖТФ, 2018, том 44, вып. 21 
что планарный волновод, нагруженный брюстеровским призменным устройством связи, может также служить источником контролируемых внутрирезонаторных потерь.

\section{Список литературы}

[1] Khomchenko A.V. Waveguide spectroscopy of thin films. N.Y.: Academic Press, 2005. $228 \mathrm{p}$.

[2] Соколов В.И., Марусин Н.В., Панченко В.Я., Савельев А.Г., Семиногов В.Н., Хайдуков Е.В. // Квантовая электроника. 2013. Т. 43. № 12. С. 1149-1153.

[3] Сотский А.Б., Steingart L.M., Jackson J.H., Парашков С.О., Дзен И.С., Сотская Л.И. // ЖТФ. 2015. Т. 85. В. 8. С. 116-123.

[4] Хомченко А.В. // Изв. РАН. Сер. физ. 2016. Т. 80. № 4. С. 471-476.

[5] Baev V.M. , Latz T., Toschek P.E. // Appl. Phys. B. 1999. V. 69. N 3. P. 171-202.

[6] Csele M.S. Laser modeling. A numerical approach with algebra and calculus. London-N. Y.: CRC Press, Taylor \& Francis Group, 2014. 260 p. 